\title{
Clinical experience with a novel assay measuring cytomegalovirus (CMV)-specific CD4+ and CD8+ T-cell immunity by flow cytometry and intracellular cytokine staining to predict clinically significant CMV events
}

Ralph Rogers ${ }^{1}$, Kapil Saharia², Aditya Chandorkar², Zoe F. Weiss ${ }^{1,3}$, Kendra Vieira' ${ }^{1}$, Sophia Koo ${ }^{3}$ and Dimitrios Farmakiotis ${ }^{1 *}$ (D)

\begin{abstract}
Background: Cytomegalovirus (CMV) infection is one of the most common opportunistic infections following organ transplantation, despite administration of CMV prophylaxis. CMV-specific T-cell immunity (TCI) has been associated with reduced rates of CMV infection. We describe for the first time clinical experience using the CMV TCell Immunity Panel (CMV-TCIP), a commercially available assay which measures CMV-specific CD4+ and CD8+ Tcell responses, to predict clinically significant CMV events.

Methods: Adult (> 18-year-old) patients with CMV-TCIP results and $\geq 1$ subsequent assessment for CMV DNAemia were included at Brown University and the University of Maryland Medical Center-affiliated hospitals between 4/ 2017 and 5/2019. A clinically significant CMV event was defined as CMV DNAemia prompting initiation of treatment. We excluded indeterminate results, mostly due to background positivity, allogeneic hematopoetic cell transplant $(\mathrm{HCT})$ recipients, or patients who were continued on antiviral therapy against CMV irrespective of the CMV-TCIP result, because ongoing antiviral therapy could prevent a CMV event.
\end{abstract}

Results: We analyzed 44 samples from 37 patients: 31 were solid organ transplant recipients, 4 had hematologic malignancies, 2 had autoimmune disorders. The CMV-protection receiver operating characteristic (ROC) area under the curve (AUC) was significant for \%CMV-specific CD4+ (AUC: 0.78, P<0.001) and borderline for CD8+ (AUC: 0.66, $P=0.064)$ T-cells. At a cut-off value of $0.22 \%$ CMV-specific CD4+ T-cells, positive predictive value (PPV) for protection against CMV was $85 \%$ (95\% Cl 65-96\%), and negative predictive value (NPV) was 67\% (95\%Cl 41-87\%).

Conclusions: The CMV-TCIP, in particular \%CMV-specific CD4+ T-cells, showed good diagnostic performance to predict CMV events. The CMV-TCIP may be a useful test in clinical practice, and merits further validation in larger prospective studies.

Keywords: CMV, Cytomegalovirus, Transplantation, Immunoassays, (val)ganciclovir

\footnotetext{
* Correspondence: dimitrios.farmakiotis@lifespan.org

${ }^{1}$ Division of Infectious Diseases, Department of Internal Medicine, Warren

Alpert Medical School of Brown University, 593 Eddy Street, Gerry House 111,

Providence, RI 02903, USA

Full list of author information is available at the end of the article
} 


\section{Background}

Cytomegalovirus (CMV) infection remains one of the most prevalent opportunistic infections (OI) following solid organ transplantation (SOT), and in individuals with hematologic malignancies or other immunocompromising conditions [1-3]. It is associated with significant morbidity due to its direct (CMV disease) and indirect (other OI, rejection, chronic allograft dysfunction) effects $[1,2,4]$. Prevention strategies after SOT consist of universal prophylaxis, preemptive therapy, or a combination of the two $[1,2]$. However, these strategies have their respective pitfalls. For example, the optimal duration of antiviral prophylaxis is uncertain, varying from as short as 3 months to $>1$ year $[1,2,5]$. Despite antiviral prophylaxis, patients may still develop CMV infection following discontinuation of prophylaxis [5-7]. In addition, there are risks of medication side-effects from antiviral prophylaxis, risk of drug resistance with prolonged antiviral prophylaxis, and the cost of antivirals can be prohibitive. Preemptive monitoring strategies can be inconvenient due to the need for serial viral load (VL) monitoring (every $1-2$ weeks) [1, 2, 6-8].

The development of CMV infection and severity of CMV disease are largely influenced by the ability of the immune system to control viral replication. This generally requires intact humoral and cell-mediated immune responses, of which the latter is a frequent target of immunosuppressant therapy in SOT recipients. Despite treatment with $\mathrm{T}$-cell inhibiting medications, most SOT recipients do not develop CMV infection, which suggests many individuals are able to maintain $\mathrm{T}$-cell responsiveness against CMV. Much effort has been expended searching for a good measure of immune competency against $\mathrm{CMV}$, including both global (non-pathogen specific) and CMV-specific assays [2]. An ideal diagnostic test that could provide a measure of immune competency to control CMV infection might allow for personalized anti-CMV care.

To this end, several CMV-specific assays evaluating cell-mediated immunity (CMI) have been developed: The Quantiferon -CMV assay exposes whole blood to $21 \mathrm{CMV}$ epitopes. Interferon gamma (IFN- $\gamma$ ) released from activated CD8+ T-cells is then quantified via ELISA, allowing for a measure of CMV-specific CD8+ (but not $\mathrm{CD} 4+$ ) $\mathrm{T}$-cell response [8-16]. The T-Track

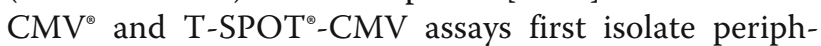
eral blood mononuclear cells (PBMC), then expose them to a variety of CMV antigens or lysates; the resulting IFN- $\gamma$ is quantified via ELISpot allowing for a measure of aggregate CMV-specific CD4+/CD8+ Tcell and NK-cell response, but not its individual components [17-26]. None of these assays are commercially available in the United States (US).
The Viracor ${ }^{\circ}$ CMV T-cell Immunity Panel (CMVTCIP) is the first commercially available assay measuring CMV-specific CMI in the US. CMV-TCIP is a flow cytometric assay that measures \%CMV-specific CD4+ and CD8+ T-cells separately, following stimulation of whole blood with CMV peptides and lysates [27]. In this study, we describe for the first time patient-level experience with the CMV-TCIP, and assess the potential utility of $\mathrm{CMV}$-specific CD4+ and CD8+ T-cell responses in predicting clinically significant CMV events.

\section{Methods \\ Patients}

We retrospectively studied adult (>18-year-old) patients with CMV-TCIP results and $\geq 1$ subsequent CMV-VL at Brown University and the University of Maryland Medical Center (UMMC)-affiliated hospitals, between 4/2017 and 5/2019. Clinically significant CMV events were defined as CMV DNAemia (> 1000 copies/mL [28]) or any detectable VL with symptoms suspicious for CMV infection by clinician assessment, prompting initiation of treatment.

We excluded from analysis indeterminate (due to background positivity) results, allogeneic hematopoetic cell transplant (HCT) recipients, or patients who were continued on antiviral therapy against CMV, irrespective of the CMV-TCIP result, since ongoing antiviral therapy could prevent a CMV event.

As a rule, CMV IgG donor seropositive/recipient negative $(\mathrm{D}+/ \mathrm{R}-)$ kidney and heart transplant recipients receive 6 months, CMV R+ kidney and heart transplant and all liver transplant recipients 3 months of valganciclovir prophylaxis. The duration of prophylaxis is extended in lung transplant recipients (D+/R-: lifelong, $\mathrm{R}+$ : 6-12 months). Patients with CMV infection have CMV-VL tested every 1-2 weeks for the first 2 months after discontinuation of valganciclovir. All patients with CMV-TCIP results included in analyses had $\geq 1$ subsequent CMV-VL and were followed clinically for 6 months after discontinuation of valganciclovir, or after the CMV-TCIP for patients who did not receive antiviral medications. CMV-TCIP were ordered at the time (within a week) of discontinuation of valganciclovir or low-level CMV viremia for patients not receiving valganciclovir. The study was approved by both Institutional Review Boards, in agreement with the Declaration of Helsinki (Brown IRB study approval \# 1346550, UMMC IRB study approval \# HP-00082131).

\section{CMV-TCIP}

Patient specimens were sent to the Viracor ${ }^{\circ}$ laboratory for CMV-TCIP per protocol: Whole blood samples were stimulated with either CMV pp65 peptide mix (JPT, 138 peptide mix) or CMV grade 2 antigen mixture (Microbix 
Biosystems). Additional aliquots of each sample were incubated without stimulation (negative control) or with a nonspecific mitogen, Staphylococcus aureus Enterotoxin Type B (SEB) (positive control). Samples were stimulated overnight in a $37^{\circ} \mathrm{C}$ incubator with $5 \% \mathrm{CO} 2$ and in the presence of Brefeldin A (BD Biosciences) and costimulatory CD28/49d antibody (BD Biosciences). Following overnight incubation, samples were fixed and permeabilized for intracellular cytokine staining (ICS). Fluorescent-tagged antibodies (BD Biosciences) used to stain cell surface markers included: anti-CD3+ (CD3PerCPCy5.5), CD4+ (CD4-Pacific Blue), and CD8+ (CD8-APC-Cy7). Fluorescent-tagged antibodies (BD Biosciences) used to measure T-cell activation in response to antigen stimulation included: CD69 (CD69-PECy7) and interferon- $\gamma$ (IFN- $\gamma$ FITC). Following ICS, samples were analyzed by flow cytometry (FC) using a Beckman Coulter Navios Flow Cytometer.

Based on data used to develop the assay from CMV IgG+ immunocompetent individuals, CMV-specific CD4+ or CD8+ responses $>0.2 \%$ are considered indicative of CMV-specific CMI (Fig. 1). Specifically, when analyzing a population of healthy adults, 100\% of CMV seronegative adults had CMV-specific CD4+ or CD8+ responses < $0.2 \%$, whereas $91 \%$ of CMV seropositive adults had CMVspecific CD4+ or CD8+ responses > $0.2 \%$ [27].

\section{Statistical analyses}

Data are presented as mean (standard deviation-S.D.) or median (25th-75th inter-quartile percentile range (IQR)) for variables of normal or non-normal distribution (by Kolmogorov-Smirnoff test), respectively. We compared continuous variables with Student's t, or Mann-Whitney tests for independent samples, and paired $t$ or Wilcoxon signed-rank tests for related samples. We compared categorical variables between groups using $x^{2}$ or Fisher's exact tests. We generated receiveroperating characteristic (ROC) curves to summarize diagnostic performance of tests in predicting protection from CMV. We calculated sensitivity, specificity, positive (PPV, protected against CMV) and negative (NPV, CMV event) predictive values, and their $95 \%$ confidence intervals $(95 \% \mathrm{CI})$, for cut-off values that were closest to assay validation cut-off value $(0.2 \%)$. Correlations were

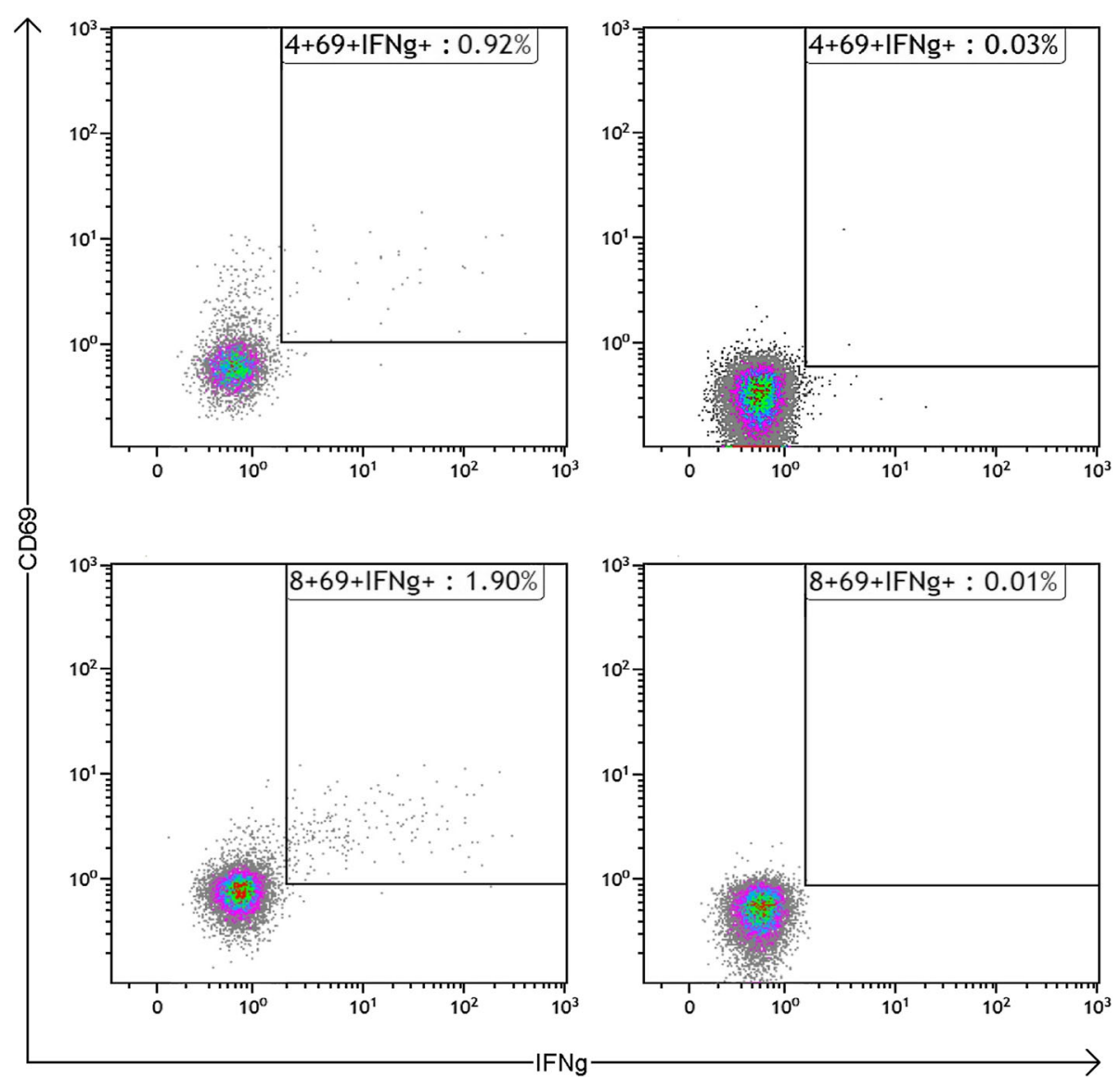

Fig. 1 CMV-TCIP flow images for CD4+ (top) and CD8+ (bottom) populations demonstrating CMV-specific response (left) or no response (right). IFNG: Interferon-gamma 
assessed by Pearson coefficient after logarithmic transformation of variables with a non-normal distribution. We used a two-tailed $\alpha$ threshold of $\leq 0.05$. Analyses were performed with SPSS statistical software, version 24, IBM Corporation (Armonk, NY, USA) and Medcalc statistical software version 12.5.0.0. (Medcalc Software, Ostend, Belgium).

\section{Results}

\section{Patients}

We identified 59 CMV-TCIP samples (Brown: 47, UMMC: 12). We excluded 8 (Brown 5, UMMC 3) indeterminate assay results (7 with high background response, one (UMMC) with CD69+ but no interferon upregulation); we also excluded 5 results from Brown, where the clinicians continued valganciclovir, one pediatric patient (also with high CD8+ background response), one allogeneic HCT recipient.
We analyzed 44 samples (Brown 35, UMMC 9) from 37 patients (Brown: 28, UMMC: 9). Thirty-one (31) were SOT recipients, of which the majority (20/31) were kidney transplant recipients. Four patients had hematologic malignancies ( 2 multiple myeloma, 1 cutaneous T-cell lymphoma treated with alemtuzumab, 1 diffuse large Bcell lymphoma and HIV) with CMV DNAemia. One patient had autoimmune colitis treated with high-dose steroids and infliximab, after which he developed proven CMV colitis. Another patient had systemic lupus erythematosus and CMV pneumonia. Clinical features of study patients at the time of CMV-TCIP are summarized in Table 1.

\section{CMV events}

We captured 16 CMV events (36\%) in 14 patients (38\%). The following parameters (at the time of CMV-TCIP) were not significantly different in patients who had

Table 1 Characteristics of the study patient population at the time of CMV-TCIP

\begin{tabular}{|c|c|c|c|}
\hline Parameter & $\begin{array}{l}\text { Patients } \\
(N=37)\end{array}$ & $\begin{array}{l}\text { CMV events } \\
(N=16)\end{array}$ & $\begin{array}{l}\text { No CMV events } \\
(N=28)\end{array}$ \\
\hline Age (years) (mean $\pm S D)$ & $56.4 \pm 15.4$ & $51.5 \pm 17.7$ & $57.9 \pm 13.6$ \\
\hline Women (\%) & $15(40.5)$ & $9(56.3)$ & $12(42.8)$ \\
\hline SOT (\%) & $31(83.7)$ & $15(93.7)$ & $23(82.2)$ \\
\hline Kidney (\%) & $20(54.1)$ & $9(56.3)$ & $15(53.6)$ \\
\hline Kidney-pancreas (\%) & $2(5.4)$ & $1(6.3)$ & $1(3.5)$ \\
\hline Heart (\%) & $6(16.2)$ & $4(25)$ & $5(17.9)$ \\
\hline Lung (\%) & $2(5.4)$ & $1(6.3)$ & $1(3.5)$ \\
\hline Liver (\%) & $1(2.7)$ & $0(0)$ & $1(3.5)$ \\
\hline High-risk for CMV (CMV D+/R-) (\%) & $20(54.1)$ & $12(75)$ & $14(50)^{*}$ \\
\hline Time from transplant (months) (median, IQR) & $11.9(7.1-17.2)$ & $10.2(8.3-18.5)$ & $12(7-16.7)$ \\
\hline \multicolumn{4}{|l|}{ Induction immunosuppression } \\
\hline Thymoglobulin (\%) & $6(16.2)$ & $4(25)$ & $5(17.9)$ \\
\hline Alemtuzumab (\%) & $6(16.2)$ & $2(12.5)$ & $4(14.2)$ \\
\hline Basiliximab (\%) & $16(43.2)$ & $8(50)$ & $11(39.3)$ \\
\hline None (\%) & $1(2.7)$ & $0(0)$ & $1(3.5)$ \\
\hline Unknown (\%) & $2(5.4)$ & $1(6.3)$ & $2(7.1)$ \\
\hline \multicolumn{4}{|l|}{ Maintenance immunosuppression } \\
\hline 2 agents (\%) & $12(32.4)$ & $6(37.5)$ & $9(32.1)$ \\
\hline 3 agents (\%) & $19(51.3)$ & $9(56.3)$ & $14(50)$ \\
\hline High-dose mycophenolate (\%) & $5(13.5)$ & $2(12.5)$ & $4(14.2)$ \\
\hline Tacrolimus trough level (ng/dL) (mean \pm SD) & $8.2 \pm 4.2$ & $8.6 \pm 4.9$ & $7.9 \pm 3.8$ \\
\hline Prednisone > 5 mg daily (\%) & $15(40.5)$ & $4(25)$ & $13(46.4)$ \\
\hline Non-SOT (\%) & $6(16.2)$ & $1(6.3)$ & $5(17.8)$ \\
\hline $\operatorname{ALC}\left(10^{9} / \mathrm{Lt}\right)($ mean $\pm \mathrm{SD})$ & $1 \pm 0.79$ & $1 \pm 0.88$ & $1 \pm 0.76$ \\
\hline
\end{tabular}

Data are presented as absolute number (\% within column) for categorical variables and mean \pm standard deviation (SD) or median (interquartile range, IQR) for continuous variables with a normal or non-normal distribution, respectively

ALC Absolute lymphocyte count, CMV D+/R- Donor positive-recipient negative CMV seropositivity status, SOT Solid organ transplant

${ }^{*} P=0.1$

${ }^{a}$ Mycophenolic acid $720 \mathrm{mg}$ or mycophenolate mofetil $1 \mathrm{~g}$ twice daily 
CMV events compared to those who did not: Age, sex, organ transplanted, time from transplant, induction immunosuppression, 3-drug maintenance immunosuppression, high-dose mycophenolate (mycophenolic acid 720 mg or mycophenolate mofetil $1 \mathrm{~g}$ twice daily), prednisone dose ( $>5 \mathrm{mg}$ daily), tacrolimus trough level, absolute lymphocyte count (ALC). As expected, more D+/RSOT recipients had CMV events (75\%), compared to other patients $(25 \%, P=0.1)$.

The \%CMV-specific CD4+ cells was significantly lower in patients with CMV events (median 0.13, IQR 0.08-0.3) compared to those without CMV events $(0.73,0.32-2.19$, $P=0.002)$. The \%CMV-specific CD8+ cells was also lower in patients with CMV events $(0.46,0.13-1.33)$ than those without CMV events $(0.9,0.37-3.75)$, though these results did not reach statistical significance $(P=0.08)($ Fig. 2).

The \%CD4+ response to SEB (positive control) was lower in patients with CMV events than those without CMV events (1.63, 0.66-3.71 vs 2.83, 1.97-4.19, $P=0.08$ ), though results did not reach statistical significance. A similar trend was also noted for \%CD8+ response to SEB (3.44, 1.54-9.47, vs 6.47, $3.28-10.27, P=0.2$ ).

\section{Diagnostic performance of CMV-TCIP}

We found a strong positive correlation between \%CMVspecific CD4+ and CD8+ T-cells $(r=0.47$ (95\% CI $0.2-$ $0.65), P=0.001$, Fig. 3).
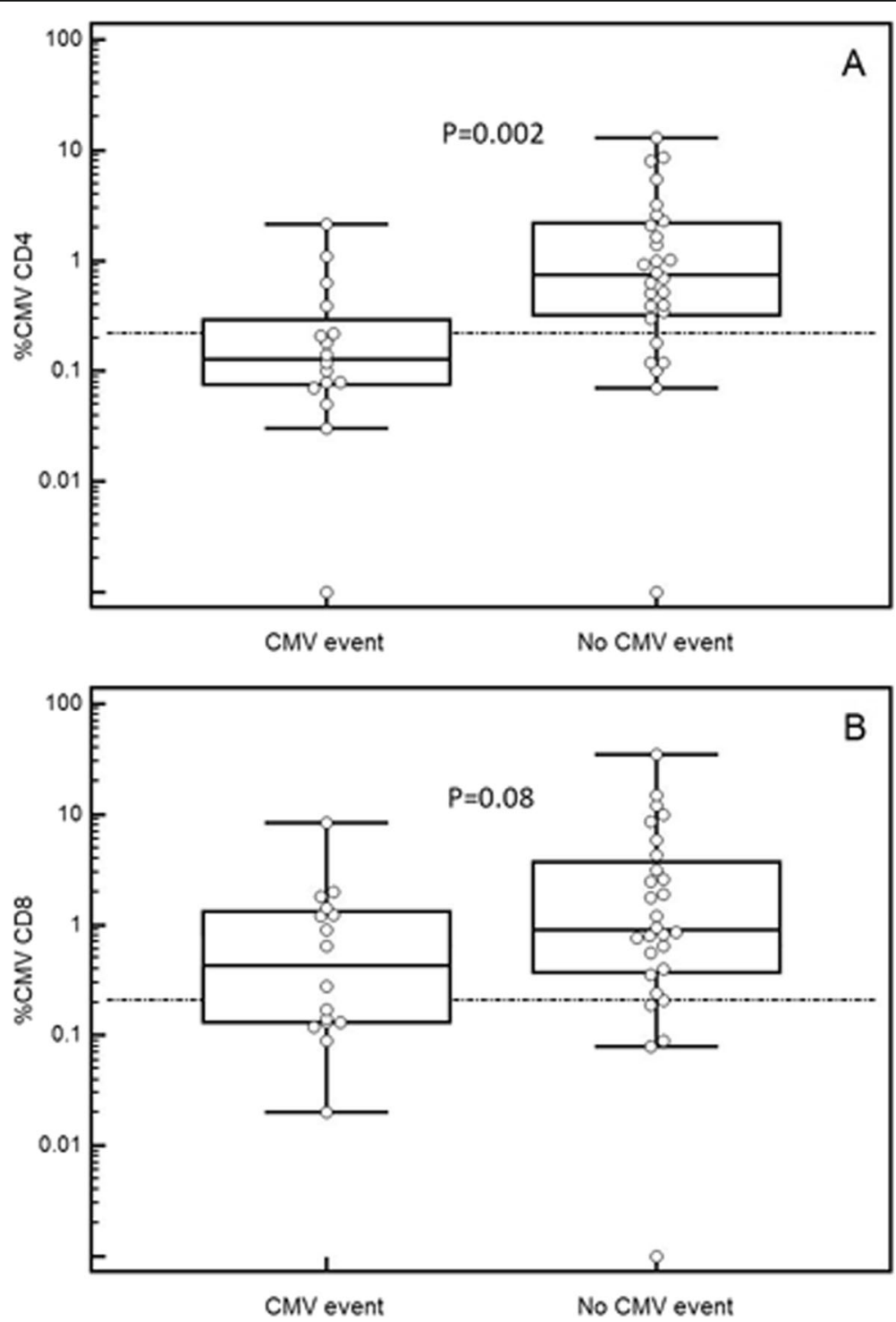

Fig. $2 \% C M V$-specific CD4+ (a Mann-Whitney $P=0.002$ ) and CD8+ (b Mann-Whitney $P=0.08$ ) T-cells in patients who subsequently had CMV events compared to those who did not (median, IQR, 1.5xIQR). Horizontal reference lines correspond to cut-off values of $0.22 \%$ (CMV-specific CD4+ T-cells), and $0.21 \%$ (CMV-specific CD8+ T-cells), as explained in the text 


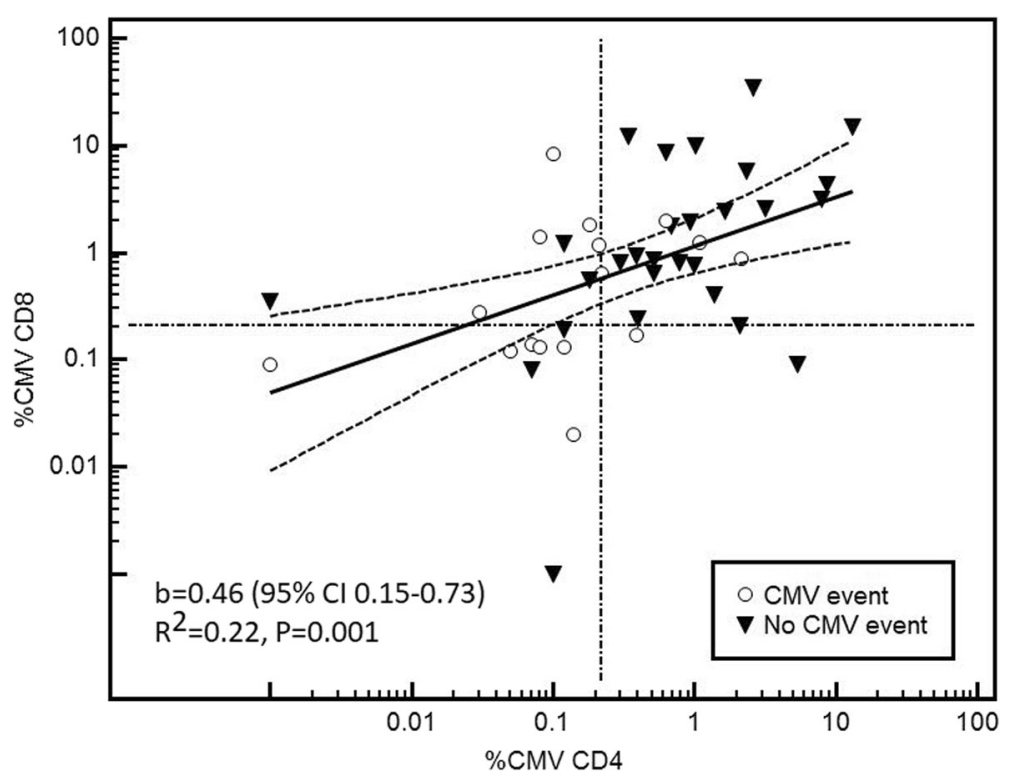

Fig. 3 Scatterplot diagram and linear regression line $(95 \% \mathrm{Cl})$ for the correlation between \%CMV-specific CD4+ and CD8+ T-cells (b: slope coefficient). The reference lines correspond to cut-off values of 0.22 and $0.21 \%$ CMV-specific CD4+ and CD8+ T-cells, respectively, as explained in the text

The CMV-protection ROC Area Under the Curve (AUC) was significant for \%CMV-specific CD4+ (AUC $0.78,95 \%$ CI $0.63-0.89, P<0.001)$ and nearly reached statistical significance for CD8+ T-cells $(0.66,0.5-0.79$, $P=0.064)$, but not for any other parameters, including absolute ALC $(0.5,0.35-0.66, P=0.96 ; P=0.008$ compared to the ROC AUC for \%CMV-specific CD4+) (Fig. 4).

We calculated sensitivity, specificity, PPV and NPV for the \%CMV-specific cut-off value from ROC curve analysis that was closest to the cut-off of $0.2 \%$, which was deemed to be indicative of CMV-specific CMI during assay development, based on the response of CMV IgG+ healthy individuals [27]. Specifically, at a cut-off value of $>0.21 \%$ CMV-specific CD8+ T-cells, sensitivity for protection against CMV was $82 \%$ (95\%CI 63-94\%), specificity $44 \%$ (20-70\%), PPV 72\% (53-86\%), NPV 58\% (28-85\%). At a cut-off value of $>0.22 \%$ CMV-specific CD4+ T-cells, sensitivity was 79\% (59-92\%), specificity 75\% (48-93\%), PPV 85\% (65-96\%), NPV 67\% (41-87\%) (Fig. 2).

As the \% of CMV events in our study was rather high, we plotted positive (PPV) and negative (NPV) predictive values of \%CMV-specific CD4+ T-cells for different frequencies of CMV events. For a pre-test probability between 15 and 25\% (the CMV event rate in most studies $[6,8,11,29]$ ), we estimated a PPV between 90 and $95 \%$ and NPV between 39 and 54\% (Fig. 5).

The peak CMV-VL after CMV-TCIP was significantly higher when $\mathrm{CMV}$-specific $\mathrm{CD} 4+\mathrm{T}$-cell response was $\leq 0.22 \%$ vs. $>0.22 \%$ (median 700 , IQR $219-1800$ vs. $0,0-$ 600 copies $/ \mathrm{mL}, P=0.005$ ) but not when CMV-specific
CD8+ T-cell response was $\leq 0.21 \%$ vs. $>0.21 \%$, where the difference did not reach statistical significance at the $P<$ 0.05 level (median 1037, IQR $0-4800$ vs. 231, 0-644 copies $/ \mathrm{mL}, P=0.13)$.

\section{Repeat CMV-TCIP}

Six patients had repeat CMV TCIP following their initial CMV event. All six were SOT recipients and 5 were high-risk for CMV (CMV D+/R-). We found a significant increase in \%CMV-specific CD4+, \%CMV-specific CD8+ (Fig. 6) and \%SEB CD4+ responses $(P=0.028)$; the increase in \%SEB CD8+ response was not statistically significant $(P=0.345)$. Five patients, all with $>0.22 \%$ CMV-specific CD4+ T-cells on repeat testing, did not experience subsequent CMV events after discontinuation of valganciclovir.

\section{False positive results}

Four (4) CMV $\mathrm{R}+$ transplant recipients with positive \%CMV-specific CD4+ responses (3 of whom also had positive CMV-specific CD8+ responses, Figs. 2 and 3) had subsequent CMV events, defined as DNAemia and initiation of treatment with valganciclovir by clinicians. Two patients (both renal transplant recipients) were restarted on valganciclovir for asymptomatic low-level CMV DNAaemia (CMV-VL were 600 and 534 copies $/ \mathrm{mL}$ ).

One heart transplant recipient with positive CMVspecific CD4+ and CD8+ responses was restarted empirically on valganciclovir for CMV DNAemia (1100 copies $/ \mathrm{mL}$ ) and oral ulcers after stopping primary prophylaxis for CMV. A second CMV-VL was also 


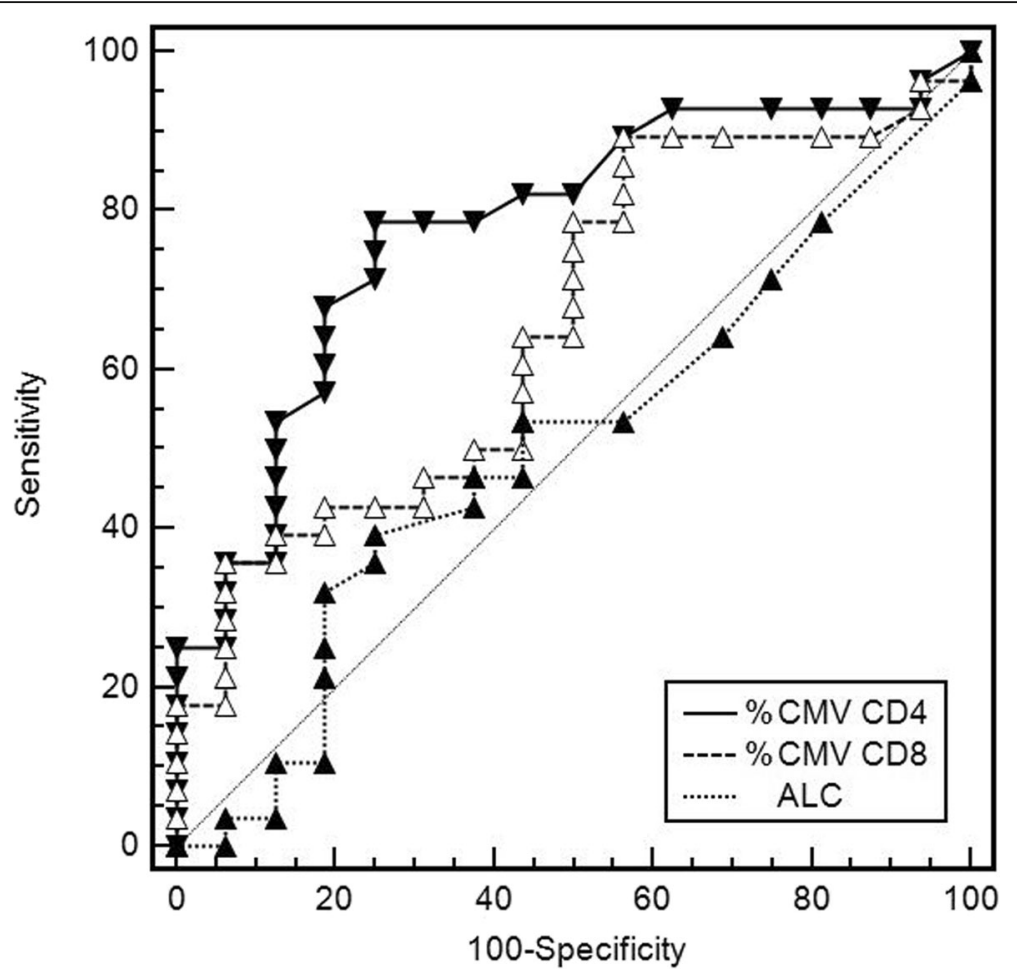

Fig. 4 Receiver-operating characteristic (ROC) curves of \%CMV-specific CD4+, CD8+ T-cells and the absolute lymphocyte count (ALC) as tests to predict subsequent CMV events. The diagonal line corresponds to area under the curve (AUC) of 0.5

detectable at 700 copies $/ \mathrm{mL}$ prior to starting treatment. No testing was performed to evaluate etiology of oral ulcer as it was presumed to be related to CMV. Valganciclovir was eventually stopped following resolution of oral ulcers and after achieving undetectable CMV-VL. There was no recurrence of CMV DNAemia. Interestingly, the oral ulcers recurred, and after appropriate testing (PCR), were found to be due to herpes simplex virus.

The fourth patient had a positive CMV-specific CD4+ but negative $\mathrm{CD} 8+$ response and had chronic diarrhea for 2 years after kidney transplant. Colonoscopy showed rare cells that were positive for CMV by immunochemistry, without cytopathic changes. He had low-level

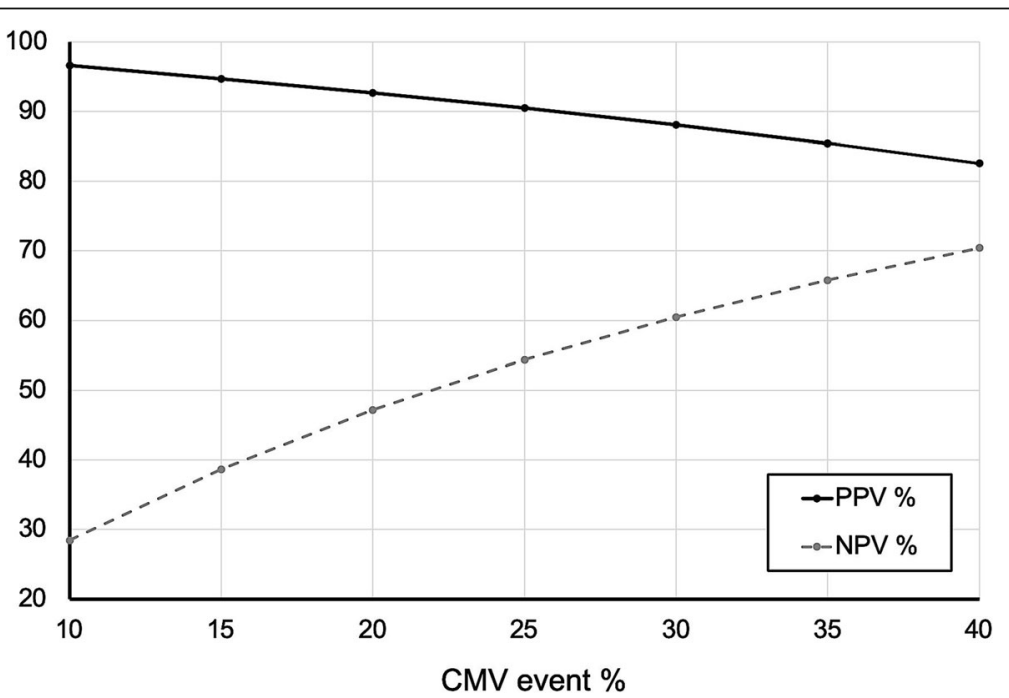

Fig. 5 Positive (PPV) and negative (NPV) predictive values of \%CMV-specific CD4+ T-cells for different frequencies (pre-test probabilities) of CMV events 


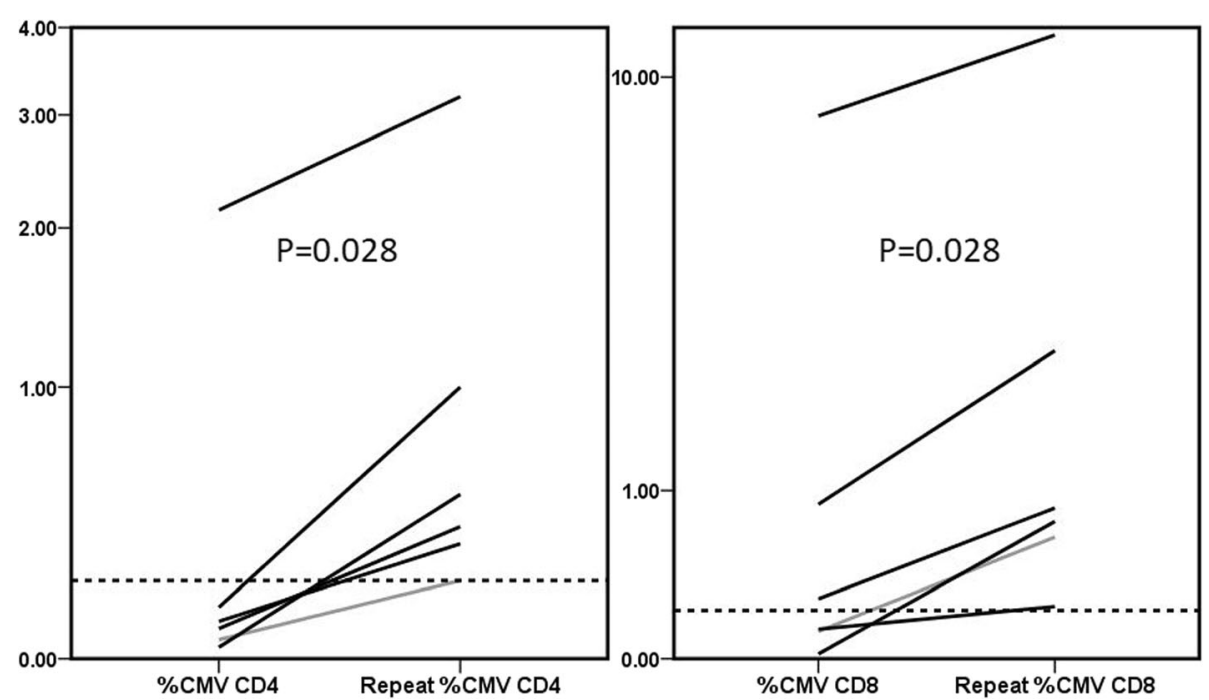

Fig. 6 Significant increases in the \% of CMV-specific CD4+ (left) and CD8+ (right) T-cells with time, after the initial CMV event (Wilcoxon rank sum $P=0.028$ ). Five of six patients (black lines), who all had $>0.22 \%$ CMV-specific CD4+ T-cells on repeat testing, did not experience subsequent CMV events after discontinuation of valganciclovir (Reference lines: 0.22 and $0.21 \%$ for CD4+ and CD8+, respectively, as explained in the text)

$(<1000)$ CMV DNAemia and was treated with valganciclovir achieving undetectable CMV-VL, but the frequency of his diarrhea did not change.

\section{Discussion}

In this study, we found a strong correlation between the results of the CMV-TCIP, specifically low CMV-specific CD4+ T-cells measured by ICS and FC, and subsequent CMV events. The association between CMV events and CMV-specific CD8+ T-cells did not reach statistical significance, although $P$-value was 0.06 (Figs. 2 and 4). In patients with repeat CMV-TCIP, CMV-specific CMI became stronger over time, facilitating discontinuation of valganciclovir (Fig. 6). Our report provides the first realworld data on the predictive value of this commercially available assay, that is supportive of its potential clinical utility.

A diagnostic test of immune competency against CMV can be utilized in different scenarios: at the end of primary prophylaxis, to determine if extended prophylaxis or close VL monitoring might be of benefit [10-16, 18, $22,25]$; at the end of treatment of CMV infection, to support the need for secondary prophylaxis $[6,8]$; finally, in patients with asymptomatic CMV DNAemia, to determine if antiviral treatment is truly indicated $[12,13,17$, 23, 29]. Herein, the CMV-TCIP performed well in a relatively small (but comparable in size to other similar studies $[8,12,29,30])$ case series, including all three potential scenaria. Larger-scale prospective studies should evaluate clinical utility of the assay in each.

Over the last decade, there has been growing interest in the development and bedside implementation of CMV-CMI assays. The Quantiferon-CMV assay can predict late-onset CMV disease after primary prophylaxis [10-16] and spontaneous clearance of CMV DNAemia [12, 13, 29]; it has also been used in two interventional studies to guide primary [16] or secondary (after treatment for a CMV event) [8] prophylaxis. ELISPOT-based CMV-CMI assays (TTrack $\mathrm{CMV}^{\circ}$ and $\mathrm{T}-\mathrm{SPOT}^{\circ}-\mathrm{CMV}$ ) can also help predict CMV events [17-26]. It should be noted though that, at the time of this manuscript, these assays are limited to research use only in the US.

When comparing CMV-CMI assays, one study demonstrated that an ELISPOT-based assay performed similar to the Quantiferon ${ }^{-}$-CMV assay [31], while a recent meta-analysis suggests that ELISPOT-based CMV-CMI testing might perform better than Quantiferon ${ }^{\circ} \mathrm{CMV}$ in predicting CMV events [32]. While the CMV-TCIP has been studied less than the above assays, the methods on which it is based (ICS/FC) have served as the goldstandard of immunoassays for years [30, 33]. Also, the predictive performance of the test in our study was comparable to previous reports, especially after adjustment for pre-test probability (Fig. 5).

The relevance of individual $\mathrm{CD} 4+/ \mathrm{CD} 8+\mathrm{T}$-cell subpopulations in the immune response to $\mathrm{CMV}$ infection in SOT recipients has been extensively studied, primarily via ICS/FC [30]. One early study of renal transplant recipients showed that presence of CMV-specific CD4+, not CD8+, T-cells was protective against development of CMV disease [34]. On the contrary, a study of heart and lung transplant recipients suggested that CMV-specific $\mathrm{CD} 8+$, not $\mathrm{CD} 4+, \mathrm{T}$-cells were protective [35]. More 
recently, a study of CMV-specific T-cell subpopulations in renal transplant recipients demonstrated that low pretransplant CD8+ T-cells, low post-transplant day (PTD) 15 CD4+ or CD8+ T-cells, and low PTD60 and PTD180 CD4+ T-cells were predictive of subsequent CMV events [36]. Given the complex interactions between subpopulations of the cellular immune system, it is likely that both CMV-specific CD4+ and CD8+ T-cells play a role in the immune response to CMV infection [30].

A limitation of the Quantiferon-CMV assay is that is seems to be more skewed towards CD8+ response. ELISPOT-based CMV-CMI testing, while measuring both $\mathrm{CD} 4+$ and $\mathrm{CD} 8+$ responses, does not provide detailed analysis of the individual components. The CMVTCIP is the only clinical test of CMV-specific CMI to date that analyzes $\mathrm{CD} 8+$ and $\mathrm{CD} 4+\mathrm{T}$-cell responses separately. CMV-specific CD4+ T-cells are necessary to generate a pool of memory cytotoxic CD8+ T-cells, that can potentially prevent disease, by controlling recurrent CMV viremia, in the absence of antiviral medication [30, 37]. This mechanism could account for the strong association of \%CMV-specific CD4+, more than CD8+ Tcells with protection against CMV in our study, and the better performance of ELISPOT-based CMV-CMI testing, compared to the Quantiferon ${ }^{\circ} \mathrm{CMV}$ in predicting CMV events [32]. Importantly, there is also evidence that $\mathrm{CD} 4+\mathrm{T}$ cells have direct antiviral properties against CMV and play an essential role in abrogating reactivation and controlling primary CMV infection [38-40]. Given the importance of both CD4+ [4, 30, 34, 36, 41, 42] and CD8+ [35, 41, 42] T-cells in the immune response to CMV, and the variety of clinical scenarios in which CMI assays may be used, detailed information regarding both CD4+ and CD8+ specific responses could be of clinical utility.

Recently, investigators have also examined measures of global immunity to predict subsequent CMV events, focusing on inexpensive tests, that most clinicians order routinely $[6,43]$. One such study in SOT recipients showed that the absolute lymphocyte count (ALC) at the completion of CMV treatment was independently associated with risk for subsequent recurrent CMV events [6], in agreement with another report studying SOT and HCT recipients [43]. We did not find a significant correlation found between ALC and risk for subsequent CMV event (Fig. 4). This discrepancy may be related to the higher rate of lymphocyte depletion (use of antilymphocyte induction therapy and HCT) in these reports, compared to our patient population.

Limitations of our study are its retrospective design, small sample size, host diversity and clinical scenarios in which this test was ordered. Our endpoint was initiation of antiviral for CMV guided by DNAemia or symptoms at clinician discretion, rather than CMV disease as defined by consensus criteria [44]. Nevertheless, clinicians frequently initiate treatment at high-level or rising CMV DNAemia before symptoms develop, therefore investigators have previously used this "real-world" outcome as a clinical endpoint when studying a CMV-CMI assay [26]. Last, providers were not blinded to test results, which might have influenced clinical thresholds to treat CMV DNAemia and choose observation over treatment with valganciclovir in patients with positive CMVTCIP values. However, this does not seem to be the case, since patients with false positive CMV-TCIP results were classified as such because clinicians decided to start treatment. None of these patients had symptoms and signs clearly attributable to CMV infection, and at least two had evidence of controlling the infection (downtrending viremia), prior to initiation of valganciclovir. Also, peak CMV-VL was higher in cases with TCIP negative results, which argues against the clinicians having a lower threshold to treat CMV in such patients.

It should be noted that, besides CD69 and IFN- $\gamma$, other activation/memory markers like CCR7, CD45RO, CD27, CD62L and cytokines like TNF- $\alpha$ and IL2 of $\mathrm{CD} 4+$ and CD8+ T-cells may be helpful to further delineate CMV-specific TCI. In one small study of CMV R+ lung transplant recipients at risk for CMV infection, sensitivity was numerically lower but specificity higher for $\%$ TNF- $\alpha$-producing CD8+ T-cells, while specificity was numerically higher for \%TNF- $\alpha$-producing CD4+ Tcells with the same sensitivity, compared to IFN- $\gamma$. IL2 had lower sensitivity and specificity compared to IFN- $\gamma$, whilst combining IFN- $\gamma$ and IL2 did not improve predictive performance [45]. Future studies might help identify even more sensitive and specific CD4/8 "deep immunophenotyping" [46] and "polyfunctional signatures" [47], to predict protection against CMV.

\section{Conclusions}

The CMV-TCIP assay, in particular \%CMV-specific $\mathrm{CD} 4+\mathrm{T}$-cells, demonstrated good performance in predicting subsequent CMV events in immunocompromised patients at risk for CMV infection. Given the potential clinical utility of this assay, further validation in larger prospective studies is warranted.

\footnotetext{
Abbreviations

ALC: Absolute lymphocyte count; AUC: Area Under the Curve; Cl: Confidence intervals; CMI: Cell mediated immunity; CMV: Cytomegalovirus; FC: Flow cytometry; HCT: Hematopoietic cell transplant; HIV: Human

Immunodeficiency Virus; ICS: Intracellular cytokine staining; IQR: Inter-quartile percentile range; NPV: Negative predictive values; Ol: Opportunistic infections; PBMC: Peripheral blood mononuclear cells; PCR: Polymerase chain reaction; PPV: Positive predictive values; PTD: Post-transplant day; ROC: Receiver operating characteristic; SEB: Staphylococcus aureus Enterotoxin Type B; SOT: Solid organ transplantation; TCI/TCIP: T-cell immunity/ T-Cell Immunity Panel; UMMC: University of Maryland Medical Center; VL: Viral load
} 


\section{Acknowledgements}

Not applicable.

\section{Authors' contributions}

DF contributed to conception of the study. DF, RR, KS, AC and KV all contributed to the study design, data collection, data analyses and manuscript editing. SK and ZFW contributed to the study design and manuscript editing. All authors read and approved the final manuscript.

\section{Funding}

The present work was supported by a Brown Physicians Inc. Academic Assessment Grant. The funding body played no role in the design of the study and collection, analysis, and interpretation of data and in writing the manuscript.

\section{Availability of data and materials}

The datasets used and/or analyzed during the current study are available from the corresponding author on reasonable request.

\section{Ethics approval and consent to participate}

The study was approved by Lifespan and the University of Maryland Medical Center Internal Review Boards, in agreement with the Declaration of Helsinki (Brown IRB study approval \# 1346550, UMMC IRB study approval \# HP00082131). A waiver for informed consent was obtained for this study.

\section{Consent for publication}

Not Applicable.

\section{Competing interests}

DF has received consultant fees and research support by Viracor-Eurofins ${ }^{\oplus}$. SK has received research support by Merck.

\section{Author details}

${ }^{1}$ Division of Infectious Diseases, Department of Internal Medicine, Warren Alpert Medical School of Brown University, 593 Eddy Street, Gerry House 111, Providence, RI 02903, USA. ${ }^{2}$ Division of Infectious Diseases and Institute of Human Virology, University of Maryland School of Medicine, Baltimore, MD, USA. ${ }^{3}$ Division of Infectious Diseases, Department of Internal Medicine, Brigham and Women's Hospital, Harvard Medical School, Boston, MA, USA.

\section{Received: 18 September 2019 Accepted: 9 January 2020}

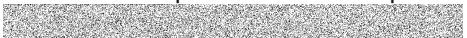

\section{References}

1. Razonable RR, Humar A. Cytomegalovirus in solid organ transplant recipients-Guidelines of the American Society of Transplantation Infectious Diseases Community of Practice. Clin Transplant. 2019;33(9):e13512.

2. Kotton CN, Kumar D, Caliendo AM, Huprikar S, Chou S, Danziger-lsakov L, et al. The third international consensus guidelines on the management of cytomegalovirus in solid-organ transplantation. Transplantation. 2018;102(6): 900-31.

3. Piukovics K, Terhes G, Gurbity-Palfi T, Bereczki A, Rarosi F, Deak J, et al. Cytomegalovirus infection in patients with haematological diseases and after autologous stem cell transplantation as consolidation: a single-centre study. Ann Hematol. 2017;96(1):125-31.

4. Tu W, Potena L, Stepick-Biek P, Liu L, Dionis KY, Luikart H, et al. T-cell immunity to subclinical cytomegalovirus infection reduces cardiac allograft disease. Circulation. 2006;114(15):1608-15.

5. Hecker M, Hecker A, Askevold I, Kuhnert S, Reichert M, Guth S, et al. Indefinite cytomegalovirus prophylaxis with valganciclovir after lung transplantation. Transpl Infect Dis. 2019;21(5):e13138.

6. Gardiner BJ, Nierenberg NE, Chow JK, Ruthazer R, Kent DM, Snydman DR. Absolute lymphocyte count: a predictor of recurrent cytomegalovirus disease in solid organ transplant recipients. Clin Infect Dis. 2018;67(9):1395402.

7. Gardiner BJ, Chow JK, Price LL, Nierenberg NE, Kent DM, Snydman DR. Role of secondary prophylaxis with valganciclovir in the prevention of recurrent cytomegalovirus disease in solid organ transplant recipients. Clin Infect Dis. 2017;65(12):2000-7.
8. Kumar D, Mian M, Singer L, Humar A. An interventional study using cellmediated immunity to personalize therapy for cytomegalovirus infection after transplantation. Am J Transplant. 2017;17(9):2468-73.

9. Walker S, Fazou C, Crough T, Holdsworth R, Kiely P, Veale M, et al. Ex vivo monitoring of human cytomegalovirus-specific CD8+ T-cell responses using QuantiFERON-CMV. Transpl Infect Dis. 2007:9(2):165-70.

10. Kumar D, Chernenko S, Moussa G, Cobos I, Manuel O, Preiksaitis J, et al. Cellmediated immunity to predict cytomegalovirus disease in high-risk solid organ transplant recipients. Am J Transplant. 2009;9(5):1214-22.

11. Manuel O, Husain S, Kumar D, Zayas C, Mawhorter S, Levi ME, et al. Assessment of cytomegalovirus-specific cell-mediated immunity for the prediction of cytomegalovirus disease in high-risk solid-organ transplant recipients: a multicenter cohort study. Clin Infect Dis. 2013;56(6):817-24.

12. Chiereghin A, Potena L, Borgese L, Gibertoni D, Squarzoni D, Turello G, et al. Monitoring of cytomegalovirus (CMV)-specific cell-mediated immunity in heart transplant recipients: clinical utility of the QuantiFERON-CMV assay for management of posttransplant CMV infection. J Clin Microbiol. 2018;56(4): e01040-17.

13. Deborska-Materkowska D, Perkowska-Ptasinska A, Sadowska A, Gozdowska J, Ciszek M, Serwanska-Swietek M, et al. Diagnostic utility of monitoring cytomegalovirus-specific immunity by QuantiFERON-cytomegalovirus assay in kidney transplant recipients. BMC Infect Dis. 2018;18(1):179.

14. Thompson G, Boan P, Baumwol J, Chakera A, MacQuillan G, Swaminathan S, et al. Analysis of the QuantiFERON-CMV assay, CMV viraemia and antiviral treatment following solid organ transplantation in Western Australia. Pathology. 2018;50(5):554-61.

15. Sood S, Haifer C, Yu L, Pavlovic J, Gow PJ, Jones RM, et al. Early viral-specific T-cell testing predicts late cytomegalovirus reactivation following liver transplantation. Transpl Infect Dis. 2018;20(5):e12934.

16. Westall GP, Cristiano Y, Levvey BJ, Whitford H, Paraskeva MA, Paul E, et al. A randomized study of Quantiferon CMV-directed versus fixed-duration valganciclovir prophylaxis to reduce late CMV after lung transplantation. Transplantation. 2019;103(5):1005-13.

17. Abate D, Fiscon M, Saldan A, Cofano S, Mengoli C, Sgarabotto D, et al. Human cytomegalovirus-specific T-cell immune reconstitution in preemptively treated heart transplant recipients identifies subjects at critical risk for infection. J Clin Microbiol. 2012;50(6):1974-80.

18. Costa C, Balloco C, Sidoti F, Mantovani S, Ritta M, Piceghello A, et al. Evaluation of CMV-specific cellular immune response by EliSPOT assay in kidney transplant patients. J Clin Virol. 2014;61(4):523-8.

19. Leone F, Gigliotti P, Mauro MV, Lofaro D, Greco F, Tenuta R, et al. Early cytomegalovirus-specific T-cell response and estimated glomerular filtration rate identify patients at high risk of infection after renal transplantation. Transpl Infect Dis. 2016;18(2):191-201.

20. Schachtner T, Stein M, Reinke P. CMV-specific T cell monitoring offers superior risk stratification of CMV-Seronegative kidney transplant recipients of a CMV-seropositive donor. Transplantation. 2017;101(10):e315-e25.

21. Favi E, Santangelo R, lesari S, Morandi M, Marcovecchio GE, Trecarichi EM, et al. Enzyme-linked immunospot assay as a complementary method to assess and monitor cytomegalovirus infection in kidney transplant recipients on pre-emptive antiviral therapy: a single-center experience. Transplant Proc. 2017;49(8):1766-72.

22. Gliga S, Korth J, Krawczyk A, Wilde B, Horn PA, Witzke O, et al. T-track-CMV and QuantiFERON-CMV assays for prediction of protection from CMV reactivation in kidney transplant recipients. J Clin Virol. 2018;105:91-6.

23. Banas B, Steubl D, Renders L, Chittka D, Banas MC, Wekerle T, et al. Clinical validation of a novel enzyme-linked immunosorbent spot assay-based in vitro diagnostic assay to monitor cytomegalovirus-specific cell-mediated immunity in kidney transplant recipients: a multicenter, longitudinal, prospective, observational study. Transpl Int. 2018;31(4):436-50.

24. Chanouzas D, Small A, Borrows R, Ball S. Assessment of the T-SPOT.CMV interferon-gamma release assay in renal transplant recipients: a single center cohort study. PLoS One. 2018;13(3):e0193968.

25. Jarque M, Melilli E, Crespo E, Manonelles A, Montero N, Torras J, et al. CMVspecific cell-mediated immunity at 3-month prophylaxis withdrawal discriminates $\mathrm{D}+/ \mathrm{R}+$ kidney transplants at risk of late-onset CMV infection regardless the type of induction therapy. Transplantation. 2018;102(11):e472-e80.

26. Kumar D, Chin-Hong P, Kayler L, Wojciechowski D, Limaye AP, Osama Gaber A, et al. A prospective multicenter observational study of cell-mediated immunity as a predictor for cytomegalovirus infection in kidney transplant recipients. Am J Transplant. 2019;19(9):2505-16. 
27. Lutgen CB, Flebbe-Rehwaldt L, Kleiboeker S, Fausett S, Cordes C, Rodgers J, et al. T-cell immunity panel measures CMV-specific CD4+ and CD8+ responses. Open Forum Infect Dis. 2017;4(Suppl. 1):S615.

28. Dioverti MV, Lahr BD, Germer JJ, Yao JD, Gartner ML, Razonable RR. Comparison of standardized cytomegalovirus (CMV) viral load thresholds in whole blood and plasma of solid organ and hematopoietic stem cell transplant recipients with CMV infection and disease. Open Forum Infect Dis. 2017:4(3):ofx143.

29. Lisboa LF, Kumar D, Wilson LE, Humar A. Clinical utility of cytomegalovirus cell-mediated immunity in transplant recipients with cytomegalovirus viremia. Transplantation. 2012;93(2):195-200.

30. Gabanti E, Bruno F, Lilleri D, Fornara C, Zelini P, Cane I, et al. Human cytomegalovirus (HCMV)-specific CD4+ and CD8+ T cells are both required for prevention of HCMV disease in seropositive solid-organ transplant recipients. PLoS One. 2014;9(8):e106044.

31. Abate D, Saldan A, Mengoli C, Fiscon M, Silvestre C, Fallico L, et al. Comparison of cytomegalovirus (CMV) enzyme-linked immunosorbent spot and CMV quantiferon gamma interferon-releasing assays in assessing risk of CMV infection in kidney transplant recipients. J Clin Microbiol. 2013;51(8):2501-7.

32. Ruan Y, Guo W, Liang S, Xu Z, Niu T. Diagnostic performance of cytomegalovirus (CMV) immune monitoring with ELISPOT and QuantiFERON-CMV assay in kidney transplantation: a PRISMA-compliant article. Medicine (Baltimore). 2019;98(16):e15228.

33. Clari MA, Munoz-Cobo B, Solano C, Benet I, Costa E, Remigia MJ, et al. Performance of the QuantiFERON-cytomegalovirus (CMV) assay for detection and estimation of the magnitude and functionality of the CMV specific gamma interferon-producing CD8(+) T-cell response in allogeneic stem cell transplant recipients. Clin Vaccine Immunol. 2012;19(5):791-6.

34. Sester M, Sester U, Gartner B, Heine G, Girndt M, Mueller-Lantzsch N, et al. Levels of virus-specific CD4 T cells correlate with cytomegalovirus control and predict virus-induced disease after renal transplantation. Transplantation. 2001;71(9):1287-94.

35. Bunde T, Kirchner A, Hoffmeister B, Habedank D, Hetzer R, Cherepnev G, et al. Protection from cytomegalovirus after transplantation is correlated with immediate early 1-specific CD8 T cells. J Exp Med. 2005;201(7):1031-6.

36. Fernandez-Ruiz M, Gimenez E, Vinuesa V, Ruiz-Merlo T, Parra P, Amat $P$, et al. Regular monitoring of cytomegalovirus-specific cell-mediated immunity in intermediate-risk kidney transplant recipients: predictive value of the immediate post-transplant assessment. Clin Microbiol Infect. 2019;25(3):381.e1-e10.

37. Wherry EJ, Ahmed R. Memory CD8 T-cell differentiation during viral infection. J Virol. 2004;78(11):5535-45.

38. Jackson SE, Sedikides GX, Mason GM, Okecha G, Wills MR. Human cytomegalovirus (HCMV)-specific CD4(+) T cells are polyfunctional and can respond to HCMV-infected dendritic cells in vitro. J Virol. 2017;91 (6):e02128-16.

39. Lachmann R, Bajwa M, Vita S, Smith H, Cheek E, Akbar A, et al. Polyfunctional T cells accumulate in large human cytomegalovirus-specific $T$ cell responses. J Virol. 2012;86(2):1001-9.

40. Swain SL, McKinstry KK, Strutt TM. Expanding roles for CD4(+) T cells in immunity to viruses. Nat Rev Immunol. 2012;12(2):136-48.

41. Gerna G, Lilleri D, Fornara C, Comolli G, Lozza L, Campana C, et al. Monitoring of human cytomegalovirus-specific CD4 and CD8 T-cell immunity in patients receiving solid organ transplantation. Am J Transplant. 2006;6(10):2356-64.

42. Nebbia G, Mattes FM, Smith C, Hainsworth E, Kopycinski J, Burroughs A, et al. Polyfunctional cytomegalovirus-specific CD4+ and pp65 CD8+ T cells protect against high-level replication after liver transplantation. Am J Transplant. 2008;8(12):2590-9.

43. Meesing A, Razonable RR. Absolute lymphocyte count thresholds: a simple, readily available tool to predict the risk of cytomegalovirus infection after transplantation. Open Forum Infect Dis. 2018;5(10):ofy230.

44. Ljungman $P$, Boeckh $M$, Hirsch HH, Josephson F, Lundgren J, Nichols G, et al. Definitions of cytomegalovirus infection and disease in transplant patients for use in clinical trials. Clin Infect Dis. 2017;64(1):87-91.

45. Clancy CJSR, Hester J, Flebbe-Rehwaldt L, Lutgen C, Yu J, Toyoda Y, Nguyen $\mathrm{MH}$. Prospective study of the kinetics of CMV-specific CD8 and CD4 responses among $\mathrm{R}+$ lung transplant recipients: identifying patients at low risk for active infections off prophylaxis. In: Interscience conference on antimicrobial agents and chemotherapy; 2011. p. 941e.

46. Camargo JF, Wieder ED, Kimble E, Benjamin CL, Kolonias DS, Kwon D, et al. Deep functional immunophenotyping predicts risk of cytomegalovirus reactivation after hematopoietic cell transplantation. Blood. 2019;133(8):867-77.
47. Snyder LD, Chan C, Kwon D, Yi JS, Martissa JA, Copeland CA, et al. Polyfunctional T-cell signatures to predict protection from cytomegalovirus after lung transplantation. Am J Respir Crit Care Med. 2016;193(1):78-85.

\section{Publisher's Note}

Springer Nature remains neutral with regard to jurisdictional claims in published maps and institutional affiliations.
Ready to submit your research? Choose BMC and benefit from:

- fast, convenient online submission

- thorough peer review by experienced researchers in your field

- rapid publication on acceptance

- support for research data, including large and complex data types

- gold Open Access which fosters wider collaboration and increased citations

- maximum visibility for your research: over $100 \mathrm{M}$ website views per year

At BMC, research is always in progress.

Learn more biomedcentral.com/submissions 